\title{
Outra via para interrogar as práticas jornalísticas
}

\author{
Beatriz Marocco' \\ http://orcid.org/0000-0003-3914-1217 \\ I - Universidade do Vale do Rio dos Sinos. \\ São Leopoldo (RS), Brasil.
}

Resumo: Parte-se de três vertentes de estudo da prática: 1. Funcionalismo, onde se situam os estudos das rotinas jornalísticas, que contribuíram para uma visão dos atos repetitivos da prática; 2 . Teoria da prática que, no final da década de 1970 e início dos anos 80, devolveu o ator ao processo social); e 3. Teoria da prática jornalística, que, mais recentemente, reúne e desenvolve quatro elementos: a prática, o desempenho/performance, o ambiente, a ordem e a mudança. Para avançar, propõe-se centralizar o eixo da investigação na escuta dos sujeitos da produção, mais pontualmente, em como estes são afetados pelo funcionamento das relações de poder. O assujeitamento e as ações de resistência, descritos em entrevistas, encontram ressonância epistemológica no pensamento e nas práticas de Michel Foucault como jornalista. Nestes termos, interrogar o funcionamento da prática jornalística supõe uma analítica da ação dos sujeitos, levando em conta os seguintes elementos: a prática, a consciência discursiva dos agentes, os procedimentos de controle discursivo, a resistência e a crítica das práticas jornalísticas.

Palavras-chave: funcionalismo; teoria da prática; jornalistas; controles discursivos; resistência.

Abstract: Another way to interrogate journalistic practices - The starting point is three theoretical strands of practice: 1 . Functionalism, where the studies of journalistic routines are located, which contributed to a view of the repetitive acts of; 2 . Theory of practice that, in the late 1970s and early 1980 s, returned the actor to the social process; and 3 . Theory of journalistic practice, that,more recently, brings together and develops four elements: practice, performance, the environment and order and change. To move forward, an epistemological turn is proposed, guided by Foucauldian practices and concepts in journalism, which makes possible to centralize the research 
axis in listening to the subjects of production, more punctually, in how they are affected by the functioning of power relations. Subjectivity and resistance actions, described in interviews, find epistemological resonance in Foucault's thinking and practices, as a journalist. In these terms, to interrogate the functioning of journalistic practice supposes an analysis of the subjects' action, taking into account the following elements: the practice and the discursive awareness of the agents, the procedures of discursive control, resistance and criticism of journalistic practices.

Keywords: functionalism; theory of practice; journalists; discursive controls; resistance.

\section{Introdução}

A interrogação que conduz este texto pertence ao nível da prática jornalística e ganha consistência afirmativa em um conjunto de teorias que descrevem o jornalista, ora refém das rotinas produtivas, ora exposto à coerção das estruturas sociais. Nas três vertentes, a questão do poder, tal como é organizado e incorporado à ordem institucional ou social, é localizada e tem peso relativo. No funcionalismo situam-se os estudos pioneiros sobre as rotinas jornalísticas, que contribuíram para uma visão dos atos repetitivos da prática (WHITE, 1950; BREED, 1955; MOLOTCH; LESTER, 1974; SCHLESINGER, 1977; GANS, 1980). Com os estudos de Bourdieu e Giddens, no final da década de 1970 e início dos anos 80, a teoria da prática devolveu o ator ao processo social. Mais recentemente, sob influência, principalmente, destes dois sociólogos, Ryfe (2017) elaborou quatro elementos de uma teoria da prática jornalística: a prática, o desempenho/performance, o ambiente, a ordem e a mudança.

Com ênfase nos sujeitos da produção, propõe-se analisar como estes são afetados pelo funcionamento das relações de poder que penetram no tecido social e se manifestam no jornalismo, quer seja nos procedimentos de controle discursivo, quer seja no assujeitamento/resistência dos sujeitos da produção. O assujeitamento e as ações de resistência, descritos em entrevistas de pesquisa e outros materiais, encontram ressonância epistemológica no pensamento e nas práticas de Foucault como jornalista. Nestes termos, interrogar o funcionamento da prática jornalística supõe uma analítica da ação dos sujeitos, levando em conta os seguintes elementos: a prática e a consciência discursiva dos agentes, os procedimentos de controle discursivo, a resistência e a crítica das práticas jornalísticas. 


\section{Rotinas}

As rotinas jornalísticas, em sua manifestação regular em ambientes de produção jornalística, têm sido estudadas há mais de 50 anos, em pesquisas voltadas para jornalistas, fontes, instituições midiáticas e ideologias dominantes. Sob a perspectiva funcionalista, as questões postas se referem à função prática das instituições, em um sistema social basicamente benigno e tendente à estabilidade, em contraposição aos marxistas, que enfatizam a natureza exploradora do capitalismo, provocando movimentos ininterruptos de desestabilização e mudança.

David Manning White inaugurou este paradigma, com o acompanhamento, durante uma semana, da tarefa diária de seleção de artigos feita por um editor telegráfico. Seis anos depois, em 1956, esta visão parcial de processo seria refutada por Walter Gieber. Para Gieber, que acompanhou o trabaIho de 16 editores de notícias de agência nos jornais diários de Wisconsin, o fator predominante era o peso da estrutura burocrática da instituição e não as avaliações pessoais que, raramente, influenciavam o processo de seleção (GIEBER, 1956, apud TRAQUINA, 1999, p. 134). Na mesma linha, Warren Breed alargou o interesse centrado na ação pessoal do gatekeeper para o espaço das redações de jornais com tiragem diária entre dez mil e 100 mil exemplares, no nordeste dos Estados Unidos (BREED, 1955, apud TRAQUINA, 1999, p. 154).

Em 1974, Molotch e Lester (apud TRAQUINA, 1999) observaram que as fontes se aproveitam das rotinas jornalísticas para as atividades de promoção de notícias. Para eles, as fontes poderosas se beneficiam ainda da capacidade de alterar as rotinas a seu favor, tendo um acesso regular aos meios de comunicação. Por este motivo, as mídias agem no sentido da manutenção de uma espécie de hegemonia ideológica no meio social, o que não impede, segundo os autores, que os jornalistas conservem uma dose elevada de autonomia no jogo que estabelecem com as fontes em torno da definição do que é notícia e dos respectivos enquadramentos. Hall et al. (1999) vão acrescentar que determinadas fontes poderosas conseguem definir os enquadramentos que dão sentido às notícias, recusando a ideia de Molotch e Lester de que os jornalistas têm grande autonomia nesse jogo. Essas fontes são classificadas pelos autores de "definidores primários" (apud TRAQUINA, 1999, p. 228).

Em relação às fontes, Gans (1980) observou que as mídias jornalísticas escoIhem as fontes de acordo com as necessidades produtivas e o posicionamento 
dessas fontes na estrutura social, assim, o seu acesso seria socialmente estratificado porque as fontes não são idênticas nem têm idêntico relevo. As empresas jornalísticas tendem à passividade, enquanto as fontes interessadas tendem à atividade.

\section{Teoria da prática}

O desafio da teoria da prática foi superar a perspectiva funcionalista vinculada à coerção dos sujeitos e ao sistema social benigno e propenso à estabilidade. No final da década de 1970 e início dos anos 80, Bourdieu e Giddens publicaram os trabalhos pioneiros. Nos últimos 20 anos, o interesse pelos fundadores cresceu. Ryfe (2017) inventariou 80 artigos científicos, capítulos de coletâneas e oito livros de autoria individual publicados na internet, em língua inglesa, voltados ao estudo das práticas jornalísticas, com aporte da teoria da prática. Do total, 35 destas publicações fizeram uma introdução à teoria da prática; 23 das 43 restantes se voltaram às ações que possibilitam a produção de notícia. Menos de um quarto do total (18 delas) incidiram em um ponto empírico primário da teoria da prática: a ordem social (entendida como prática), que é produzida e reproduzida no desempenho dos indivíduos. Neste quadro, Ryfe desenhou uma teoria da prática jornalística apoiada por um dispositivo teórico-conceitual formado principalmente por Bourdieu e Giddens, a partir de quatro elementos: a prática, o desempenho/ performance, o ambiente, a ordem e a mudança.

O primeiro elemento - a prática - engendra o "senso prático" ou "disposição" (BOURDIEU, 1977, p. 15; 1992, p. 13, apud RYFE, 2017, p. 219). Disposições (habitus ${ }^{1}$ ) são incorporadas pelos sujeitos sociais ao longo de seu processo de socialização; integram experiências passadas, atuam como uma matriz de percepções, de apreciações, de ações. Voltando-se à duração e a cognoscibilidade, Giddens (2009) aponta as práticas sociais recursivas, ordenadas no espaço e no tempo, que não são criadas por atores sociais, mas continuamente recriadas por eles em suas atividades; são composições de procedimentos generalizados ou conhecimento tácito, que integram uma consciência prática individual. Também rotineiramente, os agentes mantêm um contínuo entendimento teórico das bases de sua atividade (GIDDENS,

1 Habitus é compreendido por Bourdieu (1983, p. 65) como “[...] um sistema de disposições duráveis e transponíveis que, integrando todas as experiências passadas, funciona a cada momento como uma matriz de percepções, de apreciações e de ações - e torna possível a realização de tarefas infinitamente diferenciadas, graças às transferências analógicas de esquemas [...]. 
2009, p. 5-6). Segundo Giddens, não há barreiras entre esses dois tipos de entendimento: “Há apenas as diferenças entre o que pode ser dito e o que, de modo característico, é apenas feito" (2009, p. 8).

Ao segundo elemento concerne o desempenho dos sujeitos. Ryfe (2017) salienta o papel da habilidade de alguém socialmente qualificado, que é tido como capacitado a induzir a cooperação, atraindo e ajudando a criar significados compartilhados e identidades coletivas. Bourdieu (1972) refere-se ao "virtuose" - um jogador altamente habilidoso, permeado pelo sentido do jogo, tanto criativo, como estratégico, capacitado a manipular as condições da prática,

que descobre no opus operatur novos desencadeadores e novos suportes para o modus operandi do qual ele é o produto, de modo que seu discurso se alimenta continuamente dele mesmo, à maneira de um trem que produz seus próprios trilhos (BOURDIEU, 1972, p. 22).

Um ator social proficiente, no fluxo da atividade, é capaz de induzir a cooperação ao interpretar os saberes relativos a cada um (SEIDL, 2017, p. 241; BOURDIEU, 1990, p. 66).

Giddens sugere vincular esta função aos indivíduos que considera "hábeis sociólogos", i.e. teóricos acerca de sua própria ação. "Todos os membros competentes da sociedade são imensamente talentosos nas realizações práticas de atividades sociais e hábeis sociólogos" (2009, p. 30). Já os sociólogos de formação, que renegam esta vida social, incorrem no reducionismo do funcionalismo e do estruturalismo que procuram as origens das atividades em fenômenos que os indivíduos ignoram (2009, p. 31). Giddens critica igualmente as abordagens hermenêuticas e as versões da fenomenologia que tendem a considerar a sociedade "a criação plástica de sujeitos humanos" (idem, ibidem).

O ambiente é desenvolvido por Ryfe (2017) como terceiro elemento necessário à abordagem prática do estudo da notícia. A uma multiplicidade de termos que designam o ambiente da prática, Ryfe propõe o uso da noção de "campo", pensado por Bourdieu como um espaço de relações objetivas, regido por uma lógica e uma necessidade específicas e irredutíveis àquelas que regem outros campos que compõem o cosmo social de sociedades diferenciadas. Ryfe (2017, p. 65) organizou um conjunto de elementos fundamentais e invariantes na definição de campo, a partir de "minúsculas 
inflexões" que o conceito sofre nos diferentes usos que Bourdieu faz dele: 1) Um campo é um microcosmo incluído no macrocosmo constituído pelo espaço social global (nacional ou internacional); 2) Cada campo possui regras e desafios específicos, irredutíveis às regras e desafios de outros campos; 3) Um campo é um sistema ou um espaço estruturado de posições ocupadas por seus diferentes agentes; 4) O campo é um espaço de lutas cujo objetivo reside na apropriação do capital específico e/ou na redefinição desse capital; 5) O capital é desigualmente distribuído no seio do campo. A situação determina a estrutura do campo que é definido, portanto, pelo estado de uma relação de forças histórica entre as forças em confronto no campo; 6) Mesmo em luta, todos os agentes do campo têm interesse em que o campo exista; 7) A cada campo corresponde um habitus; apenas os agentes que tiverem incorporado o habitus têm condições de disputar o jogo; e 8) Todo campo possui autonomia relativa.

O quarto e último elemento proposto por Ryfe (2017) abarca a distensão entre ordem e mudança. Nos últimos tempos, os teóricos da prática desenvolveram as ferramentas necessárias para explicar a presença ou a ausência da ordem social. Bourdieu voltou-se a como e porque o mundo social exibe regularidades. Giddens apontou a natureza repetitiva das atividades empreendidas de maneira idêntica dia após dia e à rotinização como elemento vital para os mecanismos psicológicos por meio dos quais um senso de confiança ou segurança ontológica é sustentado nas atividades cotidianas (GIDDENS, 2009, p. XXV-XXVI).

A explicação dos teóricos para a presença da ordem social não varia e está ligada à presença do conhecimento compartilhado que constitui as práticas ordinárias e consensuadas. Neste sentido, o conceito de habitus vem responder à necessidade empírica de apreender as relações de afinidade entre o comportamento dos agentes e as estruturas e condicionamentos sociais. Bourdieu (1983) considera a ordem social como uma consequência da dominação simbólica de grupos particulares que impõem visões do que é legítimo dizer e fazer nos seus campos sociais.

Giddens (2009) introduziu a noção de dialética do controle nas práticas sociais, localizando o poder especificamente em sistemas sociais que desfrutam de certa continuidade no tempo e no espaço e se caracterizam por relações regularizadas de autonomia e dependência entre os agentes ou coletividades, em contextos de interação social. Para Giddens, o uso do 
poder não caracteriza tipos específicos de conduta, mas toda a ação, e o poder não é em si mesmo um recurso. Por outro lado, por seus vínculos com o tempo e o espaço, os campos sociais estão expostos a mudanças. Espacialmente, os campos podem se sobrepor e influenciar uns aos outros. Política e jornalismo, por exemplo. No tempo, os campos sociais podem provocar experiências de deslocamento. Outra fonte de mudança reside na motivação dos membros de grupos dominantes de continuarem sendo dominantes (FLIGSTEIN; McADAM, 2012).

\section{Discussão}

Os primeiros autores da teoria da prática lidavam com a questão do poder de várias maneiras, dando peso relativo ao poder, tal como é organizado e incorporado à ordem social ou institucional, que Giddens (2009) chama de "dominação", e/ou restringindo-o à relação social real de atores na vida concreta (on-the-ground). Já Bourdieu, em Outline of a Theory of Practice (1977), examina o poder em correlação com a noção de habitus, para enfocar o modo como os mais velhos da tribo asseguram a conformidade social, ao exercerem o "poder" no sentido prático.

[...] mas esta é uma questão relativamente menor no livro,
comparada com a elaboração que Bourdieu faz da noção
de habitus - estrutura profundamente mergulhada nas
pessoas, que plasma de tal maneira sua propensão a agir
que elas acabam amoldando-se sem que ninguém as faça
agir assim (ORTNER, 2007, p. 24).

Adotar a perspectiva dos estudos de poder, mais pontualmente a vertente foucaultiana, significa proceder a um deslocamento epistemológico do poder, como uma de muitas modalidades da prática, à centralidade que ocupa no tecido social e nas relações de poder em que se manifesta no jornalismo, quer seja nos procedimentos de controle discursivo, quer seja no assujeitamento/resistência dos sujeitos da produção. Estas operações implicam, de entrada, situar a prática dos sujeitos no nível discursivo; é na materialidade discursiva que se evidencia o conjunto de regras anônimas e históricas, determinadas no tempo e no espaço, que dão regularidade à produção. No espaço das mídias, os discursos são triplamente controlados: pela disciplina interna do jornalismo, pela ordem do discurso que opera na sociedade e pelas mídias. Os sujeitos são constituídos neste ambiente, onde agem e no qual podem ser desvendadas as suas ações, as idiossincrasias do jornalismo 
e a ordem do discurso que ali se reflete historicamente, em consonância com o regime de verdade vigente na sociedade.

Esta analítica discursiva circunscreve o campo jornalístico em funcionamento e, nele, a ação dos sujeitos. Trata-se, em síntese, de contribuição que encontra pertinência na dupla natureza - institucional e discursiva do jornalismo - e inspiração nos trabalhos foucaultianos que se ocupam dos jogos de poder e que contemplam, historicamente, a dominação, a mecânica da disciplina sobre os corpos, os procedimentos de controle discursivo. Nesta abordagem, o corpo é objeto, segundo a lógica de produção, e é arma para o contra-ataque, diferentemente de abordagens científicas do corpo que foram incorporadas à demografia ou a patologias históricas.

Para Foucault (1995), subjetivação e objetivação são processos complementares. Pondo foco nas práticas de uma dada formação discursiva, como o jornalismo, poder-se-á ter uma ideia de sua natureza, dos processos de objetivação, o modo como o sujeito pode ser tornar objeto na produção do conhecimento, e de subjetivação, o modo do ser humano constituir a si mesmo em cúmplice na sua própria constituição discursiva, em seu funcionamento na condição de sujeito discursivo.

Por ser demasiado compacta e nunca mais do que um jogo de forças, a noção de poder impedia pensar a resistência e os pontos de resistência do próprio trabalho desenvolvido por Foucault como um "filósofo da resistência às formas de vida das quais somos objetos" (PENÃFLOR, 2016, p. 297). Explicitada a necessidade de um deslocamento da fórmula saber-poder, ganha importância no pensamento foucaultiano a noção de governamentalidade - de todos e de si. Nas práticas de si, esclarece Portales (2016), o sujeito relaciona o saber à própria vida, não é objeto do sistema disciplinar, de uma "vontade de verdade"; ele é objeto de si mesmo, de sua vida. Esse sujeito foucaultiano evidencia de onde pode surgir a resistência e tem uma contingencialidade concreta: “[...] o bios do outro do que é responsável, desde o governo de si" (PORTALES, 2016, p. 263).

Seguir por esta via para a compreensão da prática desencadeou um processo de escuta dos sujeitos. A escuta dos sujeitos da prática é uma questão controversa. Foucault (1993) se vale da "ação de teoria" em vários momentos de sua trajetória. Ouve iranianos para conceber "a reportagem de ideias", frequenta os presídios para a escuta de presidiários e reconhece a potência teórica do conhecimento dos sujeitos que não são ouvidos por teóricos e 
jornalistas. Simultaneamente, em sua ação de teoria, reconhece a prática na instância discursiva. "Ilusão biográfica", por outro lado, é o termo usado por Bourdieu (2006) para colocar sob suspeita as histórias contadas. Giddens (2009) reconheceu que as atitudes manipulatórias dos atores a respeito da sua atividade têm sido uma frequente fonte de preocupação para filósofos e observadores da cena social. Para Giddens (2009, p. 5), "isso é de interesse relativamente pequeno comparado com as vastas 'áreas cinzentas' existentes entre dois estratos de processos inacessíveis à consciência discursiva dos atores".

Na junção dessas diferenças sobre a escuta dos sujeitos, acredita-se que, em sua potência dialógica (MORIN, 2000; MEDINA, 1990), a entrevista possa ser usada como ferramenta central, mais próxima das práticas (em seu desdobramento de gênero jornalístico), e mais apropriada para operar no nível da reflexividade das práticas, em que se materializa o que os agentes são capazes de dizer acerca das condições sociais e espaciais de sua própria ação. Em sua potência de dispositivo de revelação da "consciência discursiva" dos agentes (GIDDENS, 2009, p. 440), a entrevista pode engendrar um espaço autônomo, em que se desenha, de entrada, um entendimento teórico das bases de sua própria atividade. Essa potência da entrevista, como metodologia de acesso às práticas, colocou-a na centralidade da pesquisa em que foram realizadas 17 entrevistas em profundidade, de outubro de 2010 a dezembro de 2011 (MAROCCO, 2012). A saliência no mercado, a menção de nomes pelos jornalistas que responderam previamente a um questionário enviado por e-mail2, e os nomes de colegas mencionados durante as próprias entrevistas, foram critérios para seleção dos entrevistados e continuidade das entrevistas.

\section{Coerção e resistência}

Tem-se no caso do jornalismo um elenco singular de procedimentos de controle discursivo que afetam as práticas. Os procedimentos externos se referem a uma ordem do discurso fundamentada em uma "prodigiosa maquinaria" destinada a excluir todos aqueles, sejam jornalistas, sejam fontes, a procurarem contorná-la (FOUCAULT, 1996, p. 19-20; MAROCCO, 2015). 
Os procedimentos internos de controle discursivo são exercidos pelo próprio discurso (FOUCAULT, 1996, p. 21), incluem os princípios de classificação, ordem e distribuição, e são relacionados ao comentário, ao autor e às disciplinas. Na natureza jornalística não há lugar para o comentário. Tuchman (1999), neste sentido, afirma que o processamento da notícia não deixa tempo para a análise epistemológica reflexiva. Nesse sentido, os jornalistas necessitam de uma "noção operativa" de objetividade para minimizar os riscos potenciais dos prazos de entrega dos materiais produzidos, dos processos por difamação e das reprimendas dos superiores. A autoria no jornalismo não pode ser relacionada diretamente à função deautor, à medida que esta interfere na obra e nos textos como uma forma de ordem (FOUCAULT, 1996, p. 26). O autor é pressionado a levar em conta a unidade dos textos assinados por ele. É pressionado a revelar ou ao menos dar indícios de autoria para passar ao texto a sua autoridade. No texto jornalístico, essa autoridade se delineia no estilo autoral, mas é diluída no coletivo da redação, nas marcas discursivas de impessoalidade, ou seja, em uma não autoria em seus efeitos de objetividade.

Diferentemente dos procedimentos de controle do comentário e do autor, a disciplina regula as proposições mais gerais, que não estão ligadas a textos ou autores e pode ser vista, igualmente, como uma regulação interna com vistas a produzir efeitos sobre a recepção. "A disciplina é um princípio de controle da produção do discurso. Ela Ihe fixa os limites pelo jogo de uma identidade que tem a forma de uma reatualização permanente das regras" (FOUCAULT, 1996, p. 36). Ancorada nas variáveis tempo e espaço, que dão consistência de presente social de referência ao acontecimento, a disciplina possibilita que o jornalista tome decisões rápidas relativamente à validade, fiabilidade e "verdade" para levar a cabo o processamento da informação e a edição das notícias.

O último conjunto de controles discursivos pode ser visto como procedimentos nem totalmente externos, nem totalmente internos. São processos de "rarefação" dos sujeitos que falam e que, no caso jornalístico, constituem uma hierarquia organizacional. A hierarquia jornalística pode ser entendida como dispositivo de controle interno - para coleta, classificação e ordenamento dos materiais -, mas não pode ser tomada como uma forma de controle das pessoas de fora da profissão, que têm ou não acesso às mídias e que formam ou não os seus públicos. 
A tensão entre os controles discursivos, anteriormente expostos, e a resistência dos repórteres tem sido visibilizada no curso de pesquisas desenvolvidas desde 2009. Neste sentido, pode-se dar relevância à tensão existente entre duas figuras discursivas. 1) Figura que ensina a prática jornalística e faz funcionar o discurso da formação, seu regime de verdade. 2) Figura complexa, que se desdobra em vários tipos, que atua como ponto de reprodução das "táticas" próprias que não reconhecem ou que neutralizam os controles da redação, que resiste à segregação do outro e que se distancia radicalmente da autoralidade coletiva, alçando o estatuto de autor (MAROCCO, 2012, 2012a).

Entre os jornalistas que fizeram carreira nas empresas, geralmente atingindo a função de editores ou diretores de redação, entrevistados na pesquisa Os controles discursivos e o saber jornalístico que circula nas redações (MAROCCO, 2009, 2015), foi possível inventariar traços da primeira figura. No jogo de poder dentro da instituição, ou mesmo fora dela, no ambiente acadêmico, estes jornalistas desenvolveram qualidades como percepção aguçada da política empresarial, autodidatismo, envolvimento com as coisas do trabaIho, para fazer diferença, obsessão pelo furo, faro etc. Nas margens, compreendidas como outro espaço que se configura, simultaneamente, dentro e fora das mídias, a prática de alguns repórteres foi surpreendida em condições de possibilidade, quase-impermeáveis a fatores ligados ao negócio das mídias, que Edward Ross relacionou, em meados do século passado, às "vacas sagradas do jornalismo" (ROSS, apud BERGER, MAROCCO, 2008, p. 96). No âmbito da reportagem, espreitou-se outros atributos dessa figura singular. No bojo dessa figura, o repórter tem se dedicado a ouvir fontes populares, frequentado as ruas, se aproximado dos movimentos sociais. Ao abrir mão do distanciamento obtido com a "objetividade jornalística", herdada do cientificismo, o repórter apresenta-se como um sujeito que se expõe à experiência, descreve suas sensações, reconhece a alteridade. Em síntese: o repórter dispara uma ação discursiva em que, para além da obrigação de dizer a verdade, em torno da qual o jornalismo se constituiu como campo, engaja-se, como sujeito ético, no dizer a verdade.

Esta atitude crítica em relação à instituição se contrapõe aos atributos ou fórmulas do sistema de controle jornalístico, que não acarreta riscos e, com isso, oferece um lugar asséptico ao invés de ascético. Concretamente, em sua autonomia de sujeito, o repórter demonstra que é possível agir às margens do jornalismo dominante; abre mão da clássica posição de distanciamento obtida com a "objetividade jornalística", herdada do cientificismo, 
apresentando-se como um corpo que se coloca no lugar de emergência do acontecimento, se expõe à experiência, reconhece a alteridade e descreve suas sensações. Sob essas novas condições de possibilidade, o repórter se reconhece como sujeito histórico e toma para si o desenvolvimento de uma relação de comunicação que possibilitará a participação do outro como indivíduo ativo, não somente fonte da informação.

No conjunto de entrevistas foi possível compreender as práticas de autonomização e como estas diferenciam os sujeitos, pelo modo de produção e pelo comportamento em relação a si e aos outros. Assim como na primeira figura, estes sujeitos não podem ser esboçados em uma figura monolítica. Em ação, eles ocupam um gradiente de comportamentos que se desvia da norma e se tem materializado nas seguintes características, esboçadas nas pesquisas realizadas desde 2009: 1) presença do corpo e exposição às sensações na relação dialógica com o outro. Essa atitude contraria a racionalidade do saber jornalístico, que impõe a neutralidade do repórter, com a suspensão da experiência subjetiva; 2) governamentalidade dos sujeitos do jornalismo para fazer valer a sua liberdade de sujeito e a relação com os outros, que se constitui na própria matéria da ética (FOUCAULT, 2006); 3) desenvolvimento de um trabalho intelectual que aproxima jornalista e filósofo nas ações de acontecimentalização, para acionar as técnicas de produção da crítica ao jornalismo, sob a forma de reconhecimento do presente (FOUCAULT, 1980; MAROCCO; ZAMIN; BOFF, 2014). Neste sentido, a forma reducionista da pirâmide invertida é substituída pelo poliedro de inteligibilidade (idem, ibidem); 4) crítica das práticas jornalísticas. Exige um trabalho de reflexão sobre os fundamentos da racionalidade jornalística que são válidos no campo institucional e um trabalho de negação das formas de subjetivação que foram impostas pela máquina de produção jornalística. Nesse sentido, a crítica empreendida estará mais centrada na descoberta do próprio conhecimento com o qual o indivíduo "não terá mais que escutar o obedeça; ou antes, que o obedeça estará fundado sobre a autonomia mesma" (FOUCAULT, 1990, p. 6); 5) função diferenciada para a fonte jornalística. Foucault lança as bases de uma nova função para a fonte jornalística nos trabalhos do Grupo de Investigações sobre as Prisões (GIP) e nas reportagens que fez sobre a revolução do Irã. Nos dois acontecimentos, a fonte se constitui como sujeito de seu próprio discurso, não ocupa um lugar em que se Ihe oprime a um modelo pré-determinado. Essa relação libertadora da função de assujeitamento potencializará uma mudança na 
realidade desse sujeito (MAROCCO, 2008); 6) associação entre produção de reportagens diferenciadas e autoria de outros materiais. Seja na literatura, seja no documentarismo, na reportagem, ou no "livro de repórter", certos repórteres provocam um giro na autoralidade jornalística e estendem o jornalismo das mídias dominantes para outros espaços (MAROCCO, 2018).

O repórter, que rompe os limites da formação para atuar nas margens das mídias jornalísticas, formula uma figura complexa que associa uma atitude ética, em que relaciona o saber jornalístico à própria vida. Há um estreito parentesco de tal prática com a perspectiva foucaultiana desenvolvida na "reportagem de ideias" (MAROCCO, 2008), na qual a fonte não corresponde à autoridade, não tem o ônus da prova, nem da verdade, e nem terá uma forma jornalística prescrita nos livros de estilo. Está francamente em oposição ao modo de objetivação jornalística dos indivíduos que, geralmente, ocupam posições institucionais, fornecem a informação mais rapidamente, a baixo custo e, por isso, são mais produtivas e conferem à informação aparência de maior confiança e de verdade. Os repórteres que fazem valer a sua autonomia para dar protagonismo a outros sujeitos e criticar o jornalismo das mídias dominantes, dentro ou fora delas, evidenciam proximidade histórica com o modo de ser do filósofo, ou com o que Vattimo (2016) chamou, mais recentemente, de "novo intelectual". Na perspectiva foucaultiana, este jornalista se compromete com a verdade no lugar mesmo do nascimento das ideias — os acontecimentos — como se pode acompanhar nas reportagens produzidas para o Corriere della Sera sobre o Irã, o que nos levou a avançar na relação de contiguidade entre jornalista, verdade, acontecimento e poliedro de inteligibilidade.

\section{Considerações conclusivas: como, então, estudar a prática jornalística?}

Por que estudar a prática, dando ênfase às teorias do poder, ou, em outras palavras, por que considerar a validade de uma teoria da prática jornalística? Em primeiro lugar, porque é no âmbito da prática que o jornalismo se mostra organizado, epistemologizado como saber que circula nos ambientes profissionais e materializado (nos discursos da mídia). Em quatro séculos, o processo de produção passou por ciclos: a prática discursiva foi afetada por condições de possibilidade históricas, em que a informalidade dos empréstimos da literatura foi substituída pela objetividade da ciência, embora até hoje esse dilema entre os dois polos não tenha se resolvido de modo satisfatório. 
O que se propôs é um deslocamento do proselitismo, que aprofunda o desvão entre as práticas no nível de produção e a produção de discursos acadêmicos. Com o aporte da consciência discursiva dos agentes (GIDDENS, 2009), dando centralidade à distensão entre procedimentos de controle discursivo e resistência, foi possível reconhecer e problematizar o deslocamento das práticas rotinizantes à crítica das práticas jornalísticas pelos agentes e a sua autonomização em sujeitos éticos, que se libertam das marcas do modo jornalístico de objetivação dos acontecimentos e dão argumentos, para que se delineie, sobre a sua própria ação, uma "arte de não ser de tal forma governado", inventada por estes sujeitos (FOUCAULT, 1990, p. 4).

Seria utópico, no entanto, pensar que nas relações de comunicação há um estado no qual os jogos de poder, mesmo jogados por jogadores, que se reconhecem como sujeitos da própria ação, circulam sem obstáculos. Assim, o problema não é tentar dissolver as relações de poder na utopia de uma comunicação transparente, mas impor técnicas de gestão e uma prática de si que possam permitir que os jogos de poder se desenvolvam com o mínimo possível de dominação. Nesse sentido, um deslocamento da epistemologia científica, que dominou o jornalismo no século passado e que tem ganhado sobrevida com o avanço computacional, aponta na direção de um jornalismo mais ético, em que a função do jornalista predominante na epistemologia prevalecente seja reconceitualizada com o aporte das qualidades de um "intérprete moral", sem que isso signifique reforçar a dicotomia entre ciência social e humanismo, aproximando o jornalismo, por exemplo, da literatura.

Beatriz Marocco é professora na Unisinos.

beatrizmarocco@gmail.com

\section{Referências}

BOURDIEU, P. A ilusão biográfica. In: Usos e abusos da história oral. Rio de Janeiro: Fundação Getúlio Vargas, 2006, p. 183-192.

Sociologia. (Org. ORTIZ, R.). São Paulo: Ática, 1983.

Meditações Pascalianas. Rio de Janeiro: Bertrand Brasil, 2001.

. The logic of practice. California: Stanford University Press, 1990. Disponível em: <https://books.google.com.br/books?id=YHN8uW4917AC\&pg=PA66\&dq=feel+for+the+game+bourdieu\&hl=pt-PT\&sa=X\&ved=0ahUKEwjC6uPZn7vaAhVDGpAKHTUqCMMQ6AEIK-

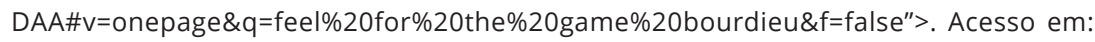


20 Ago. 2020.

. Les trois modes de connaissance e Structures, habitus et pratiques. In: Esquisse d'une théorie de la pratique. Geneve: Lib. Droz, 1972. p. 162-89. Disponível em: <https:// pt.slideshare.net/Guida2010/esboco-deumateoriadapraticapierrebourdieu">. Acesso em: 20 Ago. 2020.

Outline of a Theory of Practice. Cambridge: Cambridge University Press, 1977.

BREED, W. Controlo social da redação: uma análise funcional. In: TRAQUINA, N. Jornalismo: Questões, teorias e "estórias". Lisboa: Veja, 1999, p. 224-248.

FLIGSTEIN, N.; McADAM, D. A theory of fields. New York: Oxford University Press, 2012.

FOUCAULT, M. O que é a crítica? [Crítica e Aufklärung]. Bulletin de la Societé Française de Philosophie, v. 82, n. 2, p. 35 - 63, abr/jun 1990. Disponível em: <http://portalgens.com. br/portal/images/stories/pdf/critica.pdf>. Acesso em: 20 Ago. 2020.

. Microfísica do poder, $11^{\text {a }}$ ed. Rio de Janeiro: Graal, 1993.

O sujeito e o poder. In: DREYFUS, H.; RABINOW, P. Michel Foucault. Uma trajetória filosófica: para além do estruturalismo e da hermenêutica. Rio de Janeiro: Forense Universitária, 1995, p. 231-249.

. A ordem do discurso. São Paulo: Edições Loyola, 1996.

. Mesa redonda em 20 de maio de 1978. In: MOTTA, M. B. Foucault. Estratégia, poder-saber. Rio de Janeiro: Forense Universitária 2006.

FOUCAULT, M.; DELEUZE, G. Os intelectuais e o poder. In: FOUCAULT, M. Microfísica do poder. São Paulo: Graal, 1993, p. 69-78.

GANS, H. Deciding What's News: A Study of CBS Evening News, NBC Nightly News, Newsweek, and Time. New York: Vintage Books, 1980.

GIDDENS, A. Central problemas in social theory: action, structure and contradiction in social analysis. Berkeley, CA: University of California Press, 1979.

A constituição da sociedade. $3^{a}$ ed. São Paulo: Martins Fontes, 2009.

HALL, S. et al. A produção social das notícias: O mugging nos media. In: TRAQUINA, N. (Org.). Jornalismo: Questões, teorias e "estórias". Lisboa: Veja, 1999, p. 224-248.

MAROCCO, B. O jornalista e a prática. Entrevistas. São Leopoldo: Editora Unisinos, 2012.

. Entrevista na prática jornalística e na pesquisa. Porto Alegre: Libretos, 2012a.

Os procedimentos de controle e a resistência na prática jornalística. Galáxia, São Paulo, n. 30, p. 73-85, dez. 2015. Disponível em:<http://dx.doi.org/10.1590/19822554201522133>. Acesso em: 20 Ago. 2020. 
; ZAMIN, A.; BOFF, F. Os grandes acontecimentos e o reconhecimento do presente.

Verso e Reverso, São Leopoldo, v. 26, n. 62, p. 92-102, maio-ago. 2012.

Reportagem de transgressão, um giro no tratamento da fonte jornalística. In: BERGER, C.; MAROCCO, B. Ilha do Presídio: uma reportagem de ideias. Porto Alegre: Libretos, 2008, p. 33-47.

MEDINA, C. Entrevista. O diálogo possível. São Paulo: Ática, 1990.

Ciência e jornalismo. Da herança positivista ao diálogo dos afetos. São Paulo: Summus, 2008.

MOLOTCH, H.; LESTER, M. As notícias como procedimento intencional: acerca do uso estratégico de acontecimentos de rotina, acidentes e escândalos. In: TRAQUINA, N. (Org.). Jornalismo: Questões, teorias e "estórias". Lisboa: Veja, 1999, p. 34-51.

MORIN, E. De la entrevista. 2. ed. In: MORIN, E. Sociología. Madrid: Tecnos, 2000.

PEÑAFLOR, S. M. F. ¿Desplazamiento conceptual de la "gubernamentalidad"? acerca del gobierno de los vivos. In: MADARASZ, N.; JAQUET, G.; FÁVERO, D.; CENTENARO, N. (Orgs.). Foucault: leituras acontecimentais. Porto Alegre: Editorafi, 2016, p. 246-299. Disponível em: <https://3c290742-53df-4d6f-b12f-6b135a606bc7.filesusr.com/ugd/48d206_1f1f5c733cb04403b1e824b0c9c90cb3.pdf>. Acesso em: 18 Ago. 2020.

PORTALES, O. P. Michel Foucault: El cuidado de si y la búsqueda de una ontologia desde la particularidad. In: MADARASZ, N.; JAQUET, G.; FÁVERO, D.; CENTENARO, N. (Orgs.). Foucault: leituras acontecimentais. Porto Alegre: Editorafi, 2016, p. 245-273. Disponível em: <https://3c290742-53df-4d6f-b12f-6b135a606bc7.filesusr.com/ugd/48d206_1f1f5c733cb04403b1e824b0c9c90cb3.pdf>. Acesso em: 20 Ago. 2020.

REED, W. Controle social na redação. Uma análise funcional. In: TRAQUINA, N. (Org.). Jornalismo: Questões, teorias e "estórias". Lisboa: Veja, 1999, p. 152-166.

RYFE, David. A practice approach to the study of news production. Journalism, n. 19, v. 2, 2017, p. 217-233.

RYFE, D. News routines, role performance and change in journalism. In: MELLADO, C.; HELLMUELLER, L.; DONSBACH, W. (Eds.). Journalistic role performance. Concepts, contexts and methods. New York: Routledge, 2017a.

SCHLESINGER, P. Os jornalistas e a sua máquina do tempo. In: TRAQUINA, N. (Org.). Jornalismo: Questões, teorias e "estórias”. Lisboa: Veja, 1999, p. 177-190.

SEIDL, E. Jogo (Sentido do). In: CATANI, A. et al. Vocabulário Bourdieu. Belo Horizonte: Autêntica, 2017, p. 241-243.

TRAQUINA, N. (Org.). Jornalismo: Questões, teorias e “estórias”. Lisboa: Veja, 1999.

VATTIMO, G. Adeus à verdade. Petrópolis: Vozes, 2016. 
ZAMIN, Â. O questionário, a escuta das práticas e os comportamentos regulares no jornalismo. In: MAROCCO, B. (Org.). Entrevista na prática e na pesquisa. Porto Alegre: Libretos, 2012, p. 117-128.

WHITE, D. M. O gatekeeper: uma análise de caso na seleção de notícias. In: TRAQUINA, N. (Org.). Jornalismo: Questões, teorias e "estórias". Lisboa: Veja, 1999, p. 142-151.

Ensaio recebido em 20/09/2020 e aprovado em 14/01/2021. 